\title{
Epigenetics in congenital diseases and pervasive developmental disorders
}

\author{
Takeo Kubota
}

Received: 10 July 2007/Accepted: 24 August 2007/Published online: 11 December 2007

(C) The Japanese Society for Hygiene 2008

\begin{abstract}
Epigenetics is an intrinsic mechanism that alters gene function - not by altering DNA sequences, but by chemically modifying the DNA and chromosomal histone proteins. Epigenetics is involved in genomic imprinting and $\mathrm{X}$-chromosome inactivation in humans, and the failure of this mechanism causes a subset of congenital syndromes and cancers. Until recently, it has been believed that epigenetic modification is stable and that the pattern is faithfully preserved following DNA replication during cell division, leading to stable epigenomic patterns during one's life-time. However, more recent reports of environmental stress altering the epigenomic patterns within a short time frame after birth, followed by alterations in gene expression and phenotype, indicate that epigenetics is not only involved in congenital neurodevelopmental diseases but also in acquired diseases, including pervasive developmental disorders, through gene-environmental interaction. In this review, I introduce the subject of congenital diseases with abnormalities in known epigenetic mechanisms and discuss possible epigenetic abnormalities in pervasive developmental disorders.
\end{abstract}

Keywords Autism - DNA methylation - Environment . Epigenetics $\cdot$ Pervasive developmental disorders

This article is based on a paper presented at the Epigenetic Medicine Research Symposium at the 77th Annual Meeting of the Japanese Society for Hygiene held in Osaka, Japan on March 25-28, 2007.

T. Kubota $(\square)$

Department of Epigenetics Medicine,

Interdisciplinary Graduate School of Medicine and Engineering,

University of Yamanashi, 1110 Shimokato, Chuo,

Yamanashi 409-3898, Japan

e-mail: takeot@yamanashi.ac.jp

\section{Introduction}

It is a well-established paradigm that most diseases are caused by both genetic and environmental factors. Numerous studies presented at the annual meeting of the Japanese Society for Hygiene showed that environmental factors which can damage DNA strands are associated with carcinogenesis. However, the mechanism that operates between the genes and the environmental factors still remains to be elucidated in detail. Several lines of more recently published evidence suggest that the epigenetic mechanism, which alters gene function, can be affected by environmental factors. This in turn provides us a new insight - that a geneenvironmental interaction via epigenetic mechanism may be associated with neurodevelopmental and mental diseases.

Social environmental factors are known to contribute to the development of character in childhood and the occurrence of depression. However, autism has recently been recognized as a disease not caused by environmental factors (e.g., maternal care), but by genetic factors, suggesting that the autistic condition is determined before birth. Weaver et al. [1] reported that DNA methylation status can be altered by mental stress shortly after birth, which in turn affects gene function in brains related to mental stress. It has also been reported that a frequent use of an antidepressant normalizes epigenetic function of a gene in the brain [2] and that epigenomic information can be different between monozygotic twins who share identical genomic information [3]. These findings suggest that pervasive developmental disorders and mental diseases may be caused by environmental factors after birth through an epigenetic mechanism.

Epigenetics is an intrinsic mechanism that alters gene function by chemically modifying DNA and chromosome histone proteins without altering the DNA sequence. When 
DNA is modified with a methyl $\left(\mathrm{CH}_{3}\right)$ residue in the $\mathrm{CpG}$ islands [cytosine followed by guanine $(\mathrm{CpG})$-rich regions] in the gene promoters, genes are usually turned off. A recent issue in Nature introduced epigenetic to the readers using an example: "If the DNA sequence of the genome is like the musical score of a symphony, then the epigenome is like the key signatures, phrasing and dynamics that show how the notes of the melody should be played" [4]. To maintain a healthy condition, we need not only the appropriate genetic factors but also the appropriate epigenetic factors.

In this review, I introduce well-established congenital diseases in which epigenetic disorders are involved. I then discuss perspective aspects in pervasive developmental disorders which may be caused by environmental factors via the epigenetic mechanism.

\section{Congenital diseases associated with genomic imprinting}

Genomic imprinting is one of the first examples of an epigenetic phenomenon discovered in humans. One of two parental alleles is inactivated epigenetically in imprinted genes, whereas both of the two parental alleles are active in most of the genes. One such imprinted gene is the SNRPN gene, located in chromosome 15q12; in this case, the maternal allele is inactivated and the paternal allele is expressed. The UBE3A gene is another imprinted gene, located in the same chromosomal region as $S N R P N$, but with the opposite imprinting (the paternal allele is inactivated; the maternal allele is expressed). Failure of expression of the former gene due to deletion of paternal chromosome 15 or abnormal methylation of the paternal allele results in Prader-Willi syndrome, which is a neurodevelopmental disease characterized by severe obesity. Failure of expression of the latter gene due to either deletion of maternal chromosome 15 or abnormal methylation of the maternal allele results in Angelman syndrome, a distinct neurodevelopmental disease that is characterized by severe epileptic seizures (Fig. 1a) [5, 6]. To date, nearly 100 imprinted genes have been identified. Imprinted genes are not distributed evenly throughout the human genome; instead they are clustered in certain genomic regions. Not only deletion (described above) but also duplication of the $15 \mathrm{q} 12$ region causes an autistic disease [7], indicating that the brain is an organ in which gene expression should be strictly regulated.

\section{Congenital diseases associated with $\mathrm{X}$-chromosome inactivation}

The sex chromosomes are different in males and females (XY in males; $\mathrm{XX}$ in females). The $\mathrm{X}$-chromosome has a
A Defect in genomic imprinting

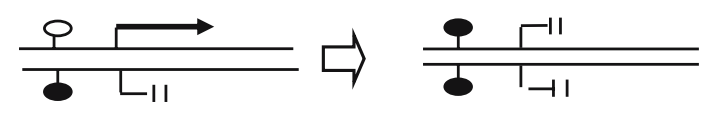

B Defect in X-chromosome inactivation

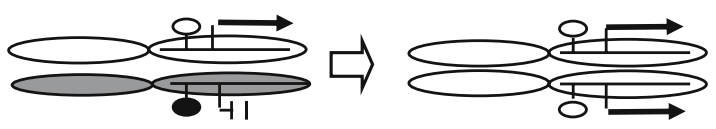

C Defect in DNA methylation

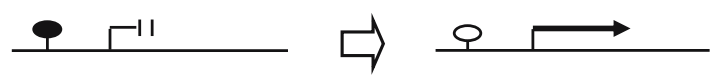

D Defect in methylated DNA-binding protein

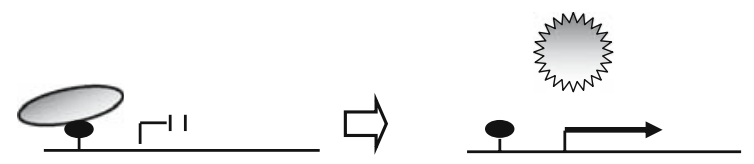

Fig. 1 Epigenetic disorders found in congenital diseases. a Genomic imprinting is referred to as mono-allelic expression depending on parental origin. The inactivated allele is methylated in its promoter region (filled circle), whereas the expressing allele is not methylated. In some pediatric diseases, both alleles are methylated, resulting in a complete lack of gene expression. b One of two X-chromosomes are normally inactivated in females. In some rare pediatric diseases, both $\mathrm{X}$-chromosomes are active, resulting in severe mental retardation. c DNA is methylated by specific enzymes, such as DNA methyltransferases (DNMTs). In a disease with immunodeficiency [immunodeficiency, centromere instability (ICF) syndrome], mutant DNMT3B fails to methylate DNA in certain genomic regions. d Genes are suppressed by epigenetic mechanism via certain proteins, such as methyl-CpG (cytosine followed by guanine-rich areas) binding proteins. In one autistic disease, denoted as Rett syndrome, mutant methyl-CpG binding protein 2 (MeCP2) fails to suppress its target genes

number of genes, whereas the Y-chromosome has only a few, indicating that females have more genes than males. To compensate for "the genetic discrimination" between females and males, one of the two $\mathrm{X}$ chromosomes in females is inactivated. The inactivated chromosome is randomly chosen between the paternally derived $\mathrm{X}$ and the maternally derived $\mathrm{X}$ in each cell during early development (Fig. 1b) [8]. If $\mathrm{X}$ inactivation does not occur during early development properly, the female fetus cannot be born. Clone animal experiments have proven this hypothesis: most cloned animals produced by somatic nuclear transfer are aborted in the middle of the fetal period, and many of such aborted cloned animals have shown failure of $\mathrm{X}$ inactivation $[9,10]$. Thus, the establishment of the appropriate methodology to achieve normal $\mathrm{X}$-inactivation is one of important conditions of successful somatic cloning [11].

Females can be born when one of $\mathrm{X}$ chromosomes is very small, even if $\mathrm{X}$-inactivation does not work properly and, consequently, both $\mathrm{X}$ chromosomes are active. 
However, such females usually have severe mental and developmental retardation, suggesting that over-expression of the $\mathrm{X}$-linked genes within the tiny $\mathrm{X}$ region has a very large effect (Fig. 1b) [12].

\section{Congenital diseases associated with defects in the epigenetic mechanism}

Recent advances in our understanding of epigenetics has resulted in the identification of many of the proteins involved in epigenetic gene regulation, including enzymes that transfer methyl (CH3)-residues onto DNA strands (the so-called methylases). Mutations of one particular methylase, DNMT3B, lead to a congenital immunodeficiency disease, immunodeficiency, centromere instability (ICF) syndrome. Patients with this syndrome are characterized by Immunodeficiency, centromere instability, and facial abnormalities. It has been demonstrated that the chromosome centromere instability (breakage near centromeric regions in chromosomes 1,9 , and 16 at the step of preparation of chromosome slides) is caused by a lack of proper methylation in heterochromatin due to a deficiency of this methylase [13-15]. However, the pathogenesis of immunodeficiency and facial abnormalities is not known, although over-expression of certain causative genes due to hypomethylation is assumed (Fig. 1c).

Methyl-CpG binding proteins (MBDs) are also epigenetic-contributing proteins. Mutations of one such MBD (MeCP2) cause an X-linked neurodevelopmental disorder (Rett syndrome) that is characterized by autism, epilepsy, and a specific hand movement (hand wrapping) $[16,17]$. Patients with Rett syndrome are all females, since males with MeCP2 mutations are embryonic lethal (X-linked dominant traits). MeCP2 protein is bound to the regulatory regions of genes and suppresses gene expression. Thus, the pathogenesis of Rett syndrome is thought to be dysregulation of MeCP2-target genes in the brain (Fig. 1d). Some of these genes have recently been identified, including the $B D N F$ gene $[18,19]$.

\section{Pervasive developmental disorders potentially associated with defects in the epigenetic mechanism}

Abnormal DNA methylation occurs in the brain within a few weeks after birth when infant mice are not well cared for by the mother, leading to abnormal behaviors in infancy [1]. This suggests that human pervasive developmental disorders can be caused by an epigenetic failure due to an environmental factor. Although numerous genetic studies in pervasive developmental disorders have been performed, to date few genes have been identified. Taken together, pervasive developmental disorders may not be caused simply by alterations in DNA sequence (i.e., mutation), but also by alterations in epigenetic regulation. This hypothesis is supported by evidence that a repair system has only been identified to date for DNA sequence - but not for epigenetic information [4].

Nutritional factors can also alter epigenetic systems. Folic acid is an essential substitute for DNA methylation, and the excess administration of folic acid to pregnant mice causes abnormal DNA methylation of a gene for pigmentation in the fetuses [20]. Nutrition lacking folic acid also alters the expression of imprinting genes in mice [21]. DNA methylation substitutes (folic acid, Vitamin B6, Vitamin B12, S-adenosyl methionine) are effective empirically in the treatment of autistic disorders and depression [22-25]. Moretti et al. [26] recently identified low levels of folic acid in the cerebral fluid samples of Rett-like patients but without $M E C P 2$ mutations and found that the administration of folic acid was an effective

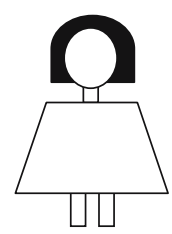

Pregnant woman

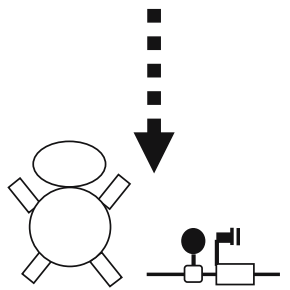

Economy switch OFF

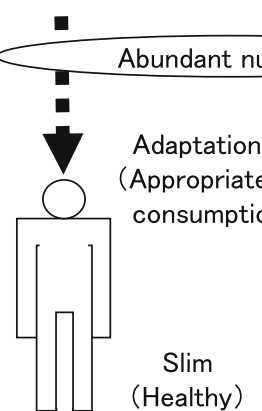

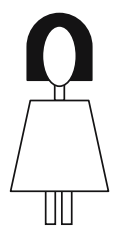

Pregnant woman on a diet

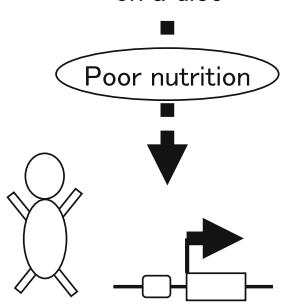

Economy switch ON

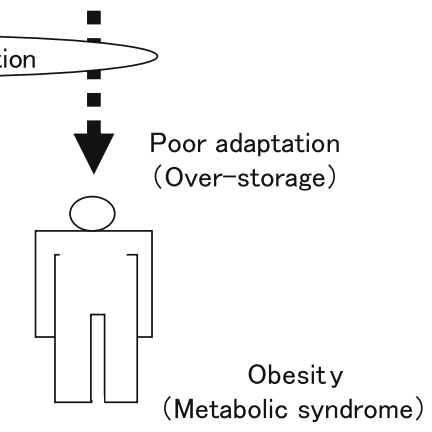

Fig. 2 Effect of epigenetic changes during fetal development. It has recently been hypothesized that poor nutrition in the uterus of a pregnant woman turns off the economy genes via the epigenetic mechanism, resulting in metabolic syndrome in adulthood due to obesity caused by the energy storage condition under abundant nutrition in societies of advanced nations [29] 
Fig. 3 Epigenetic disorders associated with geneenvironmental interaction. Until recently, congenital diseases and cancers have been considered to be the only diseases to be caused by epigenetic failures. Several lines of evidence have suggested that neurodevelopmental diseases and mental diseases are also associated with epigenetic failures. Intracytoplasmic sperm injection, a modern reproductive technique of in vitro fertilization, is thought to be associated with imprinted diseases [33]. The epigenetic effect in the fetal period is described in Fig. 2. Thus, the gene-environment interaction potentially contributes to all epigenetic diseases

\section{Epigenetic diseases}

- associated with gene-environment interaction -

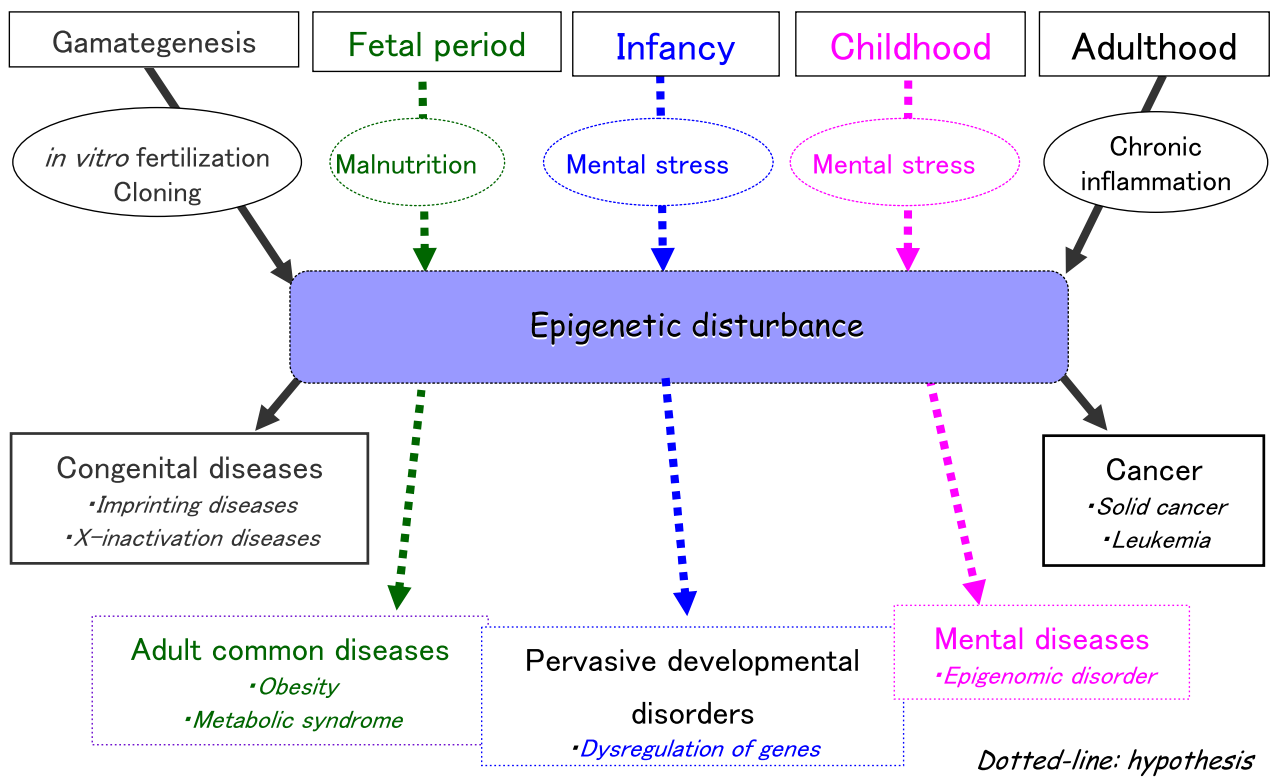

treatment for these patients. Low levels of folic acid do not necessarily indicate hypomethylation of DNA, but if it is the case, the gene that shows hypomethylation will be useful as a genetic indicator of folic acid treatment. In a similar context, folic acid was administered for a neuromuscular disease, facioscapulohumeral muscular dystrophy, in which hypomethylation was found in its causative gene region [27]; however, these researchers were unable to demonstrate that folic acid treatment had a significant effect. In the future, we may have to establish a methylation therapeutic method specific for certain genes related to a specific epigenetic disease. One such candidate molecule will be double-strand small RNAs designed in the promoter regions of causative genes [28].

The presence of environmental stress during the fetal period has been suggested as a mechanism that may alter gene expression patterns epigenetically, with these altered infants developing metabolic syndrome in adulthood [29] (Fig. 2). Figure 3 summarizes current understanding and hypotheses of the linkage between various epigenetic diseases and the possibly associated environmental factors.

\section{Outlook}

DNA methylation is dramatically changed at the cell differentiation step during early development. At this step, the pluripotency-associated genes are epigenetically inactivated, and the permanent type of epigenetic silencing safeguards against the accidental expression of these genes in differentiated cells because that might lead to dedifferentiation and to a predisposition to cancer [30]. Thus, it has a long held belief that the properly determined epigenetic pattern is maintained in each cell type for the life-time of than organism.

However, as discussed above, the epigenetic control may change at different stages during a life-time due to an environmental factor. An environmental stress (i.e., mental stress) alters DNA methylation in brain cells after birth in rats [1], suggesting that a similar phenomenon may occur in humans. If so, such an epigenetic event induced by an environmental factor in infancy may contribute to the occurrence of pervasive developmental disorders. Hyman et al. [31] and Baird et al. [32] have reported that the rates of pervasive developmental disorders and those of autism have recently increased. There is also increasing evidence that behavioral and educational interventions with young patients may improve developmental and behavioral outcomes and that basic deficits in play and communication may be therapeutically modified [31]. Therefore, when we fully understand the role of the epigenetic mechanism in pervasive developmental disorders, we will be able to identify associated environmental factors and establish an epigenetics-oriented new therapy.

Acknowledgements The author expresses his gratitude to Prof. Kanehisa Morimoto for planning the symposium of epigenetic medicine at the 77th Annual Meeting of the Japanese Society for Hygiene (Osaka) and his thanks to Prof. Yasuhito Yuasa for the opportunity to write this review. 


\section{References}

1. Weaver IC, Cervoni N, Champagne FA, D'Alessio AC, Sharma $\mathrm{S}$, Seckl JR, et al. Epigenetic programming by maternal behavior. Nat Neurosci. 2004;7:847-54.

2. Tsankova NM, Berton O, Renthal W, Kumar A, Neve RL, Nestler EJ. Sustained hippocampal chromatin regulation in a mouse model of depression and antidepressant action. Nat Neurosci. 2006;9:519-25.

3. Fraga MF, Ballestar E, Paz MF, Ropero S, Setien F, Ballestar $\mathrm{ML}$, et al. Epigenetic differences arise during the lifetime of monozygotic twins. Proc Natl Acad Sci USA. 2005;102: 10604-9.

4. Qiu J. Epigenetics: unfinished symphony. Nature. 2006;441: 143-5.

5. Nicholls RD, Saitoh S, Horsthemke B. Imprinting in Prader-Willi and Angelman syndromes. Trends Genet. 1998;14:194-200.

6. Kubota T, Das S, Christian SL, Baylin SB, Herman JG, Ledbetter DH. Methylation-specific PCR symplifies imprinting analysis. Nat Genet. 1997;16:16-7.

7. Cook EH Jr, Lindgren V, Leventhal BL, Courchesne R, Lincoln A, Shulman C, et al. Autism or atypical autism in maternally but not paternally derived proximal $15 \mathrm{q}$ duplication. Am J Hum Genet. 1997;60:928-34.

8. Kubota T, Nonoyama S, Tonoki H, Masuno M, Imaizumi K, Kojima M, et al. A new assay for the analysis of X-chromosome inactivation based on methylation-specific PCR. Hum Genet. 1999;104:49-55.

9. Xue F, Tian XC, Du F, Kubota C, Taneja M, Dinnyes A, et al. Aberrant patterns of $\mathrm{X}$ chromosome inactivation in bovine clones. Nat Genet. 2002;31:216-20.

10. Nolen LD, Gao S, Han Z, Mann MR, Gie Chung Y, Otte AP, et al. $\mathrm{X}$ chromosome reactivation and regulation in cloned embryos. Dev Biol. 2005;279:525-40.

11. Yang X, Smith SL, Tian XC, Lewin HA, Renard JP, Wakayama T. Nuclear reprogramming of cloned embryos and its implications for therapeutic cloning. Nat Genet. 2007;39:295-302.

12. Kubota T, Wakui $\mathrm{K}$, Nakamura $\mathrm{T}$, Ohashi $\mathrm{H}$, Watanabe $\mathrm{Y}$, Yoshino M, et al. Proportion of the cells with functional X disomy is associated with the severity of mental retardation in mosaic ring X Turner syndrome females. Cytogenet Genome Res. 2002;99:276-84

13. Okano M, Bell DW, Haber DA, Li E. DNA methyltransferases Dnmt3a and Dnmt3b are essential for de novo methylation and mammalian development. Cell 1999;99:247-57.

14. Shirohzu H, Kubota T, Kumazawa A, Sado T, Chijiwa T, Inagaki $\mathrm{K}$, et al. Three novel DNMT3B mutations in Japanese patients with ICF syndrome. Am J Med Genet. 2002;112:31-7.

15. Kubota T, Furuumi H, Kamoda T, Iwasaki N, Tobita N, Fujiwara $\mathrm{N}$, et al. ICF syndrome in a girl with DNA hypomethylation but without detectable DNMT3B mutation. Am J Med Genet A. 2004;129:290-3.

16. Amir RE, Van den Veyver IB, Wan M, Tran CQ, Francke U, Zoghbi HY. Rett syndrome is caused by mutations in X-linked MECP2, encoding methyl-CpG-binding protein 2. Nat Genet. 1999;23:185-8.
17. Chunshu Y, Endoh K, Soutome M, Kawamura R, Kubota T. A patient with classic Rett syndrome with a novel mutation in MECP2 exon 1. Clin Genet. 2006;70:530-1.

18. Chen WG, Chang Q, Lin Y, Meissner A, West AE, Griffith EC, et al. Derepression of BDNF transcription involves. calciumdependent phosphorylation of MeCP2. Science. 2003;302:885-9.

19. Itoh M, Ide S, Takashima S, Kudo S, Nomura Y, Segawa M, et al. Methyl CpG-binding protein 2, whose mutation causes Rett syndrome, directly regulates insulin-like growth factor binding protein 3 in mouse and human Brains. J Neuropathol Exp Neurol. 2007;66:117-23.

20. Wolff GL, Kodell RL, Moore SR, Cooney CA. Maternal epigenetics and methyl supplements affect agouti gene expression in Avy/a mice. FASEB J. 1998;12:949-57.

21. Waterland RA, Lin JR, Smith CA, Jirtle RL. Post-weaning diet affects genomic imprinting at the insulin-like growth factor 2 (Igf2) locus. Hum Mol Genet. 2006;15:705-16.

22. James SJ, Cutler P, Melnyk S, Jernigan S, Janak L, Gaylor DW, et al. Metabolic biomarkers of increased oxidative stress and impaired methylation capacity in children with autism. Am J Clin Nutr. 2004;80:1611-7.

23. Rimland B, Callaway E, Dreyfus P. The effect of high doses of vitamin B6 on autistic children: a double-blind crossover study. Am J Psychiatry. 1978;135:472-5.

24. Reynolds EH, Carney MW, Toone BK. Methylation and mood. Lancet. 1984;2:196-8.

25. Rimland B. Controversies in the treatment of autistic children: vitamin and drug therapy. J Child Neurol. 1988;3[Suppl]:S68S72.

26. Moretti P, Sahoo T, Hyland K, Bottiglieri T, Peters S, del Gaudio D, et al. Cerebral folate deficiency with developmental delay, autism, and response to folinic acid. Neurology. 2005;64:1088-90.

27. van der Kooi EL, de Greef JC, Wohlgemuth M, Frants RR, van Asseldonk RJ, Blom HJ, et al. No effect of folic acid and methionine supplementation on D4Z4 methylation in patients with facioscapulohumeral muscular dystrophy. Neuromuscul Disord. 2006;16:766-9.

28. Kim JW, Zhang YH, Zern MA, Rossi JJ, Wu J. Short hairpin RNA causes the methylation of transforming growth factor-beta receptor II promoter and silencing of the target gene in rat hepatic stellate cells. Biochem Biophys Res Commun. 2007;359:292-7.

29. Gluckman PD, Hanson MA, Spencer HG, Bateson P. Environmental influences during development and their later consequences for health and disease: implications for the interpretation of empirical studies. Proc Biol Sci. 2005;272:671-7.

30. Reik W. Stability and flexibility of epigenetic gene regulation in mammalian development. Nature. 2007;447:425-32.

31. Hyman SL, Rodier PM, Davidson P. Pervasive developmental disorders in young children. JAMA. 2001;285:3141-2.

32. Baird G, Simonoff E, Pickles A, Chandler S, Loucas T, Meldrum $\mathrm{D}$, et al. Prevalence of disorders of the autism spectrum in a population cohort of children in South Thames: the Special Needs and Autism Project (SNAP). Lancet. 2006;368:210-5.

33. Burger J, Lip V, Mau UA, Sperling K, Wu BL, Horsthemke B. Intracytoplasmic sperm injection may increase the risk of imprinting defects. Am J Hum Genet. 2002;71:162-4. 